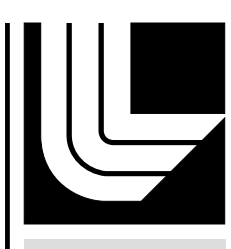

LAWRENCE LIVERM ORE NATIONAL LABORATORY

Implementation of Imaging

Thomson Scattering on the Omega Laser

J. S. Ross, D. H. Froula, A. J. Mackinnon, C. Sorce, N. Meezan, S. H. Glenzer, W. Armstrong, R. Bahr, R. Huff, K. Thorp

May 6, 2006

Review of Scientific Instruments 
This document was prepared as an account of work sponsored by an agency of the United States Government. Neither the United States Government nor the University of California nor any of their employees, makes any warranty, express or implied, or assumes any legal liability or responsibility for the accuracy, completeness, or usefulness of any information, apparatus, product, or process disclosed, or represents that its use would not infringe privately owned rights. Reference herein to any specific commercial product, process, or service by trade name, trademark, manufacturer, or otherwise, does not necessarily constitute or imply its endorsement, recommendation, or favoring by the United States Government or the University of California. The views and opinions of authors expressed herein do not necessarily state or reflect those of the United States Government or the University of California, and shall not be used for advertising or product endorsement purposes. 


\title{
Implementation of Imaging Thomson Scattering on the Omega Laser
}

\author{
J. S. Ross, D. H. Froula, A. J. Mackinnon, C. Sorce, N. Meezan, and S. H. Glenzer \\ Lawrence Livermore National Laboratory, University of California, \\ P.O. Box 808, Livermore, California 94551 \\ W. Armstrong, R. Bahr, R. Huff, and K. Thorp \\ Laboratory for Laser Energetics, University of Rochester, New York 14623
}

\begin{abstract}
Imaging Thomson Scattering has been implemented on the Omega Laser facility at the Laboratory for Laser Energetics, University of Rochester[J. M. Soures, et al., Laser and Particle Beams 11, 317 (1993)]. Using a high resolution spectrometer and an intensified CCD the electron temperature profile, ranging from $1.5 \mathrm{keV}$ to $3 \mathrm{keV}$, was measured along the axis of a $\mathrm{CH}$ gas filled hohlraum. The system integrates over $200 \mathrm{ps}$ a region $2 \mathrm{~mm}$ in length and has a spatial resolution of $50 \mu \mathrm{m}$ and a spectral resolution of $0.027 \mathrm{~nm}$. Data obtained from this diagnostic are compared to hydrodynamic simulations.

PACS numbers:
\end{abstract}




\section{INTRODUCTION}

Thomson Scattering has been a valuable diagnostic of plasma characteristics at the Omega Laser Facility[1]. It has recently been used to measure the electron temperature in a $\mathrm{Kr}$ gas-bag plasma[2] as well as the electron temperature and ion temperature in a $\mathrm{CH}$ filled hohlraum[3], both comparable to hydrodynamic simulations. The abilities of this diagnostic have recently been expanded to include Imaging Thomson Scattering (ITS) which allows spatially resolved measurements of electron temperature, $T_{e}$ and density, $n_{e}$, along a region of plasma greater than $z=2 \mathrm{~mm}$ in length. This imaging capability will allow accurate gradient measurements facilitating comparisons between experimental results and hydrodynamic simulations used in designing future inertial confinement fusion targets. ITS will help address outstanding questions regarding $T_{e}$ profiles in gas filled hohlraums and the effect of magnetic fields on electron thermal transport [4, 5].

Thomson Scattering uses a probe beam with frequency $\left(\omega_{o}\right)$ and wave number $\left(k_{o}\right)$ to scatter from electron density fluctuations with a given wave number $\left(k_{a}\right)$. When the correct wave number $\left(k_{a}\right)$ is probed $\left(Z T_{e} / T_{i}>k_{a}^{2} \lambda_{D e}^{2}\right)$ the electrons in the plasma that follow the motion of the ions dominate the scattering process. The light scattered by these electrons provides a measure of the dynamic ion structure factor, $S(\mathbf{k}, \omega)$, yielding the ion-acoustic sound speed, ion wave damping, as well as the local particle flow velocity. The sound speed is directly related to the electron temperature $\left(T_{e}\right)$,

$$
\left(\frac{\omega_{a}}{k_{a}}\right)^{2}=\frac{T_{e}}{M}\left(\frac{Z}{1+k_{a}^{2} \lambda_{D e}^{2}}+\Gamma \frac{T_{i}}{T_{e}}\right)
$$

where $\omega_{a}$ is the ion acoustic frequency, $M$ is the ion mass, $Z$ is the charge state, $T_{i}$ is the ion temperature, $\lambda_{D e}$ is the electron Debye length, and $\Gamma$ is the specific heat ratio. This technique has been widely used in the characterization of laser plasmas[6, 7].

\section{EXPERIMENTAL SETUP}

\section{A. Laser Configuration}

A high-energy, ultraviolet probe beam[8] is used for Thomson scattering at the Omega Facility. The probe operates at a wavelength of $264 \mathrm{~nm}(4 \omega)$ with a maximum energy of 200 $\mathrm{J}$ in a $1 \mathrm{~ns}$ square pulse. In addition to 1 ns-long probe laser pulses, 200 ps-long pulses may 
also be applied with a corresponding maximum energy of $40 \mathrm{~J}$. The beam is focused using a $4 \omega$ aspheric f/6.7 lens with a best vacuum focal spot of $60 \mu \mathrm{m}$.

\section{B. Imaging Thomson Scattering Diagnostic}

The Thomson scattered light of the probe laser in the plasma is collected with an achromatic fused silica f/10 lens with a focal length of $50 \mathrm{~cm}$. The optic is mounted in a Ten Inch Manipulator (TIM-2) at a distance of $50 \mathrm{~cm}$ from the plasma. The angle between TIM-2 and the input port (P9) of the $4 \omega$ probe is $79^{\circ}$. A fused silica blast shield coated to reject the light from the heater beams $(3 \omega)$ is mounted before the collection optic. The collected light is then transported by a series of turning mirrors to a $1 \mathrm{~m}$ spectrometer located $10 \mathrm{~m}$ from the target chamber. A $7.5 \mathrm{~cm}$ focusing mirror with a $75 \mathrm{~cm}$ focal length images the scattering light onto the slit of the spectrometer with a magnification of 1.5. The spectrometer uses a 3600 lines/mm grating and a $100 \mu \mathrm{m}$ entrance slit. An intensified, gated 16-bit CCD, model I-MAX-512-T, is coupled to the output of the spectrometer.

To image the hohlraum axis along the entrance slit of the spectrometer we mounted the spectrometer on a stage to rotate it around the center of the entrance slit(Fig. 1). This

procedure was preferred compared to a two-mirror periscope[9] to accommodate fast alignment. It is critical for imaging Thomson scattering to align the image of the spectrometer entrance slit in the plasma with the probe beam; if the slit is not aligned to the probe beam within $5^{\circ}$ Thomson-scattered light will not propagate through the spectrometer. The Thomson scattering volume $(60 \mu \mathrm{m} \times 60 \mu \mathrm{m} \times 2000 \mu \mathrm{m})$ is defined by the overlap of the slit image $(80 \mu \mathrm{m} \times 2000 \mu \mathrm{m})$ in the plasma with the probe beam $(60 \mu \mathrm{m}$ diameter).

\section{System Alignment}

The Thomson-scattering volume is aligned using a $100 \mu \mathrm{m}$ fiber positioned at TCC. Initial alignment is performed by injecting a $532 \mathrm{~nm}$ laser into the fiber which is directed towards the collection lens. The lens is positioned to collimate the light collected from the fiber. The light is then imaged on the slit of the spectrometer using a series of turning mirrors and a focusing mirror. Final focussing and alignment of the CCD is accomplished by imaging the slit of the spectrometer onto the CCD. When light from TTC is visible on the CCD the 
$532 \mathrm{~nm}$ laser is replaced with a $4 \omega$ laser. The system is achromatic and it is now possible to set the spectrometer grating to first order for $4 \omega$ and image the fiber at TCC through the complete system.

To confirm alignment of the $4 \omega$ probe beam a $100 \mu m$ sphere is positioned at TCC. Light scattered from the sphere is then imaged on the CCD confirming overlap of the $4 \omega$ probe beam and the Thomson scattering volume. The amount of light scattered is insufficient for initial alignment, but once the system is aligned can be easily detected.

\section{System Characterization}

The spectral resolution was measured using $\mathrm{Hg}$ lines around $310 \mathrm{~nm}$ to have a FWHM $=0.027 \mathrm{~nm}$ using a $50 \mu \mathrm{m}$ slit. The $\mathrm{Hg}$ spectra are also used to measure the spectral dispersion; the dispersion increases by $9 \%$ from $310 \mathrm{~nm}$ to the measurement region $(0.0055$ $\mathrm{nm} /$ pix at $264 \mathrm{~nm}$ ) due to the change in the grating angle.

To determine the magnification, resolution and focus of the collection system, a grid [shown in Fig. 1(a)] with known orientation to the probe beam is centered at TCC. Figure 1(b) shows an image of the grid back illuminated by $4 \omega$ light when the spectral slit has been rotated to be parallel to the probe beam axis. In this image the spectrometer is rotated by 52 degrees from its nominal vertical position used for streaked Thomson-scattering measurements. Features less than $60 \mu \mathrm{m}$ are visible indicating a spatial resolution of this order. The magnification of the system $(M=1.8)$ is measured by comparing the $1 \mathrm{~mm}$ spectral slit width to the $63.5 \mu \mathrm{m}$ grid spacing in the detector plane. Figure 1 shows the system has a large field of view along the probe beam axis $(>2 \mathrm{~mm}$ ) which allows temperature measurements along the complete $2 \mathrm{~mm}$ hohlraum axis (limited by the length of the diagnostic window in the hohlraum wall).

\section{EXPERIMENTAL RESULTS}

\section{A. Target}

The targets (Fig. 2) are gas-filled (1 atm of $1 \% \mathrm{Ar}, 29 \% \mathrm{CH}_{4}, 70 \% \mathrm{C}_{3} \mathrm{H}_{8}$ ) gold hohlraums with a length of $2 \mathrm{~mm}$ and a diameter of $1.6 \mathrm{~mm}$. The heater beams penetrate the hohlraum at one or both ends through laser entrance holes with a diameter of $0.8 \mathrm{~mm}$ which are covered 
with polyimide membranes. The targets are heated with 16-37 $3 \omega$ beams with total energies of $8 \mathrm{~kJ}$ to $17 \mathrm{~kJ}$ in a $1 \mathrm{~ns}$ flat top laser pulse with $0.1 \mathrm{~ns}$ rising and falling edges. The hohlraums are aligned along the propagation direction of the $4 \omega$ probe beam (P9 axis). A slot $1.6 \mathrm{~mm}$ in length and $0.5 \mathrm{~mm}$ in width is cut into the side of the hohlraum oriented to face the Thomson-scattering collection optics (TIM-2). The slot is covered with a polyimide membrane that is blown out by a heater beam during the experiment.

\section{B. Results}

In Figure 3 imaging Thomson-scattering data shows a large temperature gradient along the axis of the hohlraum. A 1 ns probe beam was used and an integration time of less than 200 ps was achieved by triggering the CCD gate late in the probe beam pulse. The probe beam is delayed 300 ps relative to the heater beams. This gradient was produced by only heating the target with the heater beams on one side of the hohlraum. Over a $1 \mathrm{~mm}$ region inside the hohlraum the electron temperature varies from $1.5 \mathrm{keV}$ to $3 \mathrm{keV}$. These temperatures where measured by fitting a multiple ion species form factor[10] to the experimental data. The error bars are obtained by varying the fits within the noise of the experimental data. This temperature gradient is in agreement with HYDRA simulations using a flux limited diffusion model.

\section{CONCLUSIONS}

A new imaging Thomson-scattering diagnostic has been demonstrated at the Omega laser facility. The spatial, spectral, and temporal resolutions have all been carefully measured. This diagnostic has already begun to produce high-quality data on temperature profiles in dense, high-Z plasmas, that can be used to benchmark hydrodynamic simulations. Future experiments will strive to further differentiate between a flux limited diffusion model and a nonlocal diffusion model. This work was supported by LDRD 06-ERD-056 and was performed under the auspices of the U.S. Department of Energy by the Lawrence Livermore 
National Laboratory under Contract No. W-7405-ENG-48(with University of California).

[1] J. M. Soures, R. L. McCrory, T. R. Boehly, R. S. Craxton, S. D. Jacobs, J. H. Kelly, T. J. Kessler, J. P. Knauer, R. L. Kremens, S. A. Kumpan, et al., Laser Particle Beams 11, 317 (1993).

[2] K. B. Fournier, C. Constantin, C. A. Back, L. Suter, H. K. Chung, M. C. Miller, D. H. Froula, G. Gregori, S. H. Glenzer, E. L. Dewald, et al., Journal of Quantitative Spectroscopy and Radiative Transfer 99, 186 (2006).

[3] D. H. Froula, J. S. Ross, L. M. Divol, N. Meezan, A. J. Mackinnon, R. Wallace, and S. H. Glenzer (2006), submitted to Phys Plasmas.

[4] S. H. Glenzer, W. E. Alley, K. G. Estabrook, J. S. De Groot, M. G. Haines, J. H. Hammer, J. P. Jadaud, B. J. MacGowan, J. D. Moody, W. Rozmus, et al., Physics of Plasmas 6 (1999).

[5] P. D. Nicolai, J. L. A. Feugeas, and G. P. Schurtz, Physics of Plasmas 13, (2006), 028CH Times Cited:0 Cited References Count:36.

[6] D. Montgomery, R. P. Johnson, J. A. Cobble, J. Fernandez, E. L. Lindman, H. A. Rose, and K. G. Estabrook, Laser and Particle Beams p. 349 (1999).

[7] H. A. Baldis, C. J. Walsh, and R. Benesch, Applied Optics 21, 297 (1982).

[8] A. J. MacKinnon, S. Shiromizu, G. Antonini, J. Auerbach, H. Haney, D. H. Froula, J. Moody, G. Gregori, C. Constantin, C. Sorce, et al., Review of Scientific Instruments 75, 3906 (2004).

[9] G. Gregori, S. H. Glenzer, J. Knight, C. Niemann, D. Price, D. H. Froula, M. J. Edwards, R. P. J. Town, W. Rozmus, A. Brantov, et al., Physical Review Letters 92 (2004).

[10] D. E. Evans, Plasma Physics 12, 573 (1970).

\section{Figures}



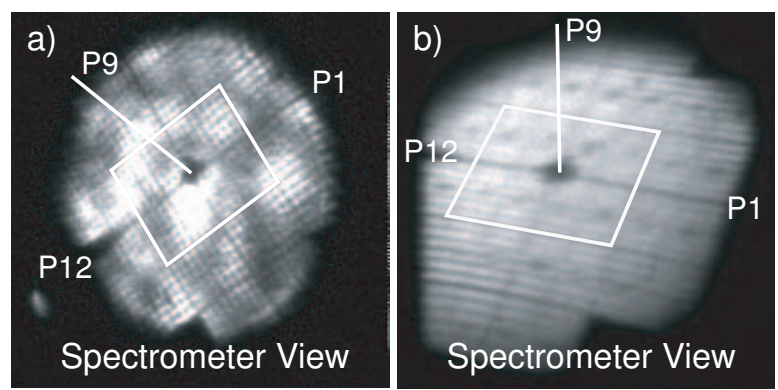

FIG. 1: The grid located at TTC is imaged using a large spectrometer entrance slit. (a) Shows the grid with the spectral slit in the nominal vertical position and (b) shows the grid after the spectrometer has been rotated $52^{\circ}$ aligning the probe beam (P9 axis) and the entrance slit.

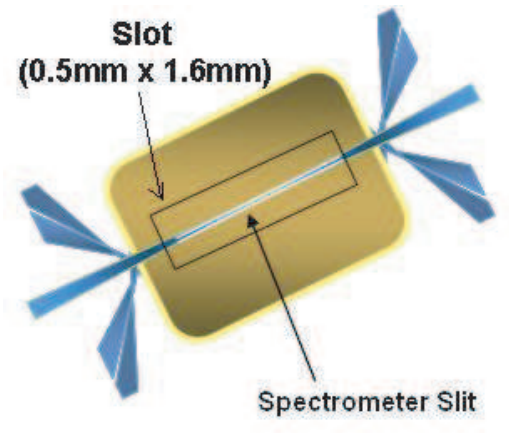

FIG. 2: 37 beams are used to heat the gas-filled hohlraum and the $4 \omega$ probe beam is aligned along the hohlraum axis. A slot $1.6 \mathrm{~mm}$ in length and $0.5 \mathrm{~mm}$ in width cut into the side of the hohlraum wall allows light scattered along the axis of the hohlraum to be collected by the imaging Thomson-scattering system.
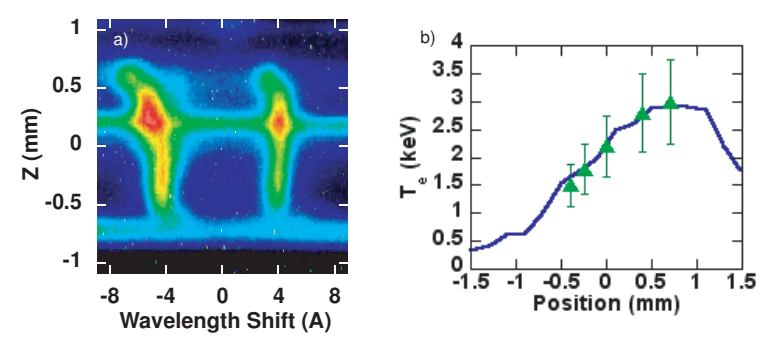

FIG. 3: (a) The Thomson-scattering spectrum shows a large temperature gradient along the axis of the hohlraum. (b) The electron temperature profile (triangles) shows close agreement with the HYDRA simulation (solid line) using a flux limited diffusion model with a flux limiter of 0.05. 